\title{
Mixed-Refining of BCTMP and LBKP for Lightweight Papers
}

\author{
Lies Indriati* Mungki Septian Romas Ike Rostika \\ Center for Pulp and Paper, Jl. Raya Dayeuhkolot no.132 Bandung 40258, Indonesia
}

\begin{abstract}
Refining of pulp is an important stage on papermaking process in developing the fiber properties in order to meet the paper quality requirements. Separate refining is general practice implemented by industry which uses more than one kind of pulp. However, combined or mixed refining of two kinds of pulp has an advantageous especially in the view of energy. Mixed refining of BCTMP (Bleached Chemi-Thermo-Mechanical Pulp) and LBKP (Leaf Bleached Kraft Pulp) mixture has been investigated. The experiments were carried out at a mixture composition of $10 \%$ BCTMP and $90 \%$ LBKP compared to the same mixture composition of pulps which were refined separately, as well as 100\% BCTMP and 100\% LBKP. The result showed that the average fiber length of pulps mixture from mixed refining was the lowest, but its' maximum fiber length was still quite good, closed to LBKP fibers. Compared to separate refining, mixed refining of pulps produced good sheet strength, while the other sheet properties were not significantly influenced.
\end{abstract}

Keywords: BCTMP, LBKP, refining, mixed refining

DOI: $10.7176 / \mathrm{CMR} / 11-8-04$

Publication date:October $31^{\text {st }} 2019$

\section{Introduction}

Wood-free fine papers are generally made from a mixture of short fibers of Leaf Bleached Kraft Pulp (LBKP) and long fibers of Needle Bleached Kraft Pulp (NBKP) with certain compositions. Long fiber contributes the strength properties of paper which facilitates the runability of paper machine, while the short fiber provides the desired final properties of paper produced, such as good formation, opacity, smoothness and internal bonding (Hu et.al., 2006; Liu, 201). The composition of furnish is varied in the range of 5\%-50\% for long fiber and $95 \%-50 \%$ of short fiber (Indriati et.al., 2016).

In order to increase its competitiveness, paper manufacturers continue to strive reducing their production costs while maintaining the quality of paper produced. One of the efforts made is by reducing or even completely eliminating the use of relatively expensive long fibers. In addition, efforts to reduce production costs can also be done by substitution a portion of fibers with fillers that is much cheaper compared to pulp.

The current development of papermaking technology has made it possible to produce wood-free writing and printing paper using $100 \%$ of short fiber from hardwood (Indriati, et.al., 2016), even with the addition of fillers up to $30 \%$. However, further efforts to save production costs are still being carried out by substituting a portion of chemical pulp fibers with cheaper pulp fibers such as mechanical pulp or also known as high yield pulp (HYP).

The use of HYP as a substitute pulp not only lowers production costs but can also produce good quality paper while maintaining sheet thickness and stiffness at lower grammage (https://www.pulpandpapercanada.com/ news/bctmp-a-pulp-for-all-reasons-1000106738). In addition, HYP contains more fines fractions so that they can improve sheet formation and opacity (Liu, 201).

The use of HYP as a substitute of wood pulp for printing paper furnish in China has reached the range of 10$20 \%$, and it's still tried to increase up to the range of $40-50 \%$. The trial of increasing HYP content from $17 \%$ to $40 \%$ in the production of coated papers was carried out at a paper factory in China. From this trial, it was found that the increase of HYP content did not affect printing properties of the resulting paper (Liu, 2014).

One type of widely used high-yield pulp is BCTMP (Bleached Chemi-Thermo Mechanical Pulp). In CTMP process, wood chips are treated by weak solution of sodium sulphite at alkaline $\mathrm{pH}$ and steam before it is defiberized using pressurized refiner. As a result of this treatment, lignin becomes soft so it facilitates defiberation process of wood fibers during the refining process (Indriati, 2016; Klinga, 2014).

In order to retain the yield, the bleaching process of CTMP is done using non-destructive bleaching chemicals such as ozone or peroxide. The technology of BCTMP is developed for both softwood and hardwood (http://www.paperonweb.com/gradepl.htm).

At present, the quality of BCTMP can be designed in such a way that it can meet the quality needs of paper products to be made. The CTMP bleaching process can achieve brightness level of $60 \%-70 \%$ ISO, and can even achieve higher brightness, as high as $80 \%-90 \%$ ISO. Low brightness BCTMP is generally utilized to substitute short wood fibers in part for tissue papers manufacturing, while the high brightness BCTMP is utilized for fine writing and printing papers, both coated and uncoated (http://www.paperonweb.com/gradepl.htm).

The strength and brightness characteristics of BCTMP fibers can be designed almost equal to LBKP with its' unique characteristics of high bulk, surface area, and fines content (Hu, et.al., 2006). Hu et.al. (2004), Gao et.al. (2009), and www.sicemsaga.com reported that the use of BCTMP to substitute LBKP can reduce fiber costs while 
improving the quality of paper sheets, specifically bulk, opacity and stiffness. However, the usage of BCTMP as fine paper furnish has limitations. It decreases paper permanence because of its high lignin content which resulted in yellowing of papers (Chen et.al., 2012; Pu et.al., 2003).

In the previous experiment, the substitution of LBKP by BCTMP in the absence of NBKP has been done. The experiment was carried out by mixing LBKP with BCTMP in various compositions. In addition, a separaterefining and combined-refining of a mixture composition of 93\% LBKP and 7\% BCTMP were also studied. The result showed that the handsheets with better smoothness, opacity, tensile and internal bonding strength were obtained from combined-refining. In contrary, the handsheets' bulk, porosity and brightness were decrease. (Indriati et al., 2016).

This paper describes a laboratory scale combined-refining trial of a mixture of 10\% BCTMP and 90\% LBKP, compared to separate refining of the same mixture composition. How the refining treatment affects the fiber morphology, the characteristics of the handsheets as well as the structure of sheet surface are reported.

\section{Refining Theory}

Refining is an important step in the stock preparation prior the stock is sent to paper machine. As a major component in papers, fibers significantly influence the final properties of papers. The refining of fibers aims to modify the fiber physical structure so that it is ready to be formed into sheet on a paper machine with the expected final properties. In the refining process, the fibers are subjected to the mechanical treatment between stator and rotor in the refiner. At the beginning step, it damages the fiber's primary wall, allowing fiber swelling to occur. The fiber swelling makes fibers become more flexible, so that mechanical actions to the fibers can takes place more easily resulted in fibrillation of fibers, both internal and external. Changes in the physical structure of fibers due to refining resulted in the increasing of fibers surface area which allows more fiber bonding to occur. These results in the improvement of strength properties of paper produced as well as the smoothness of paper surface. After reaching the optimum conditions, further mechanical action on fiber will cause fiber cutting and fines formation. This condition has a negative impact on the strength of paper. However, at some level, the formation of fines can still be tolerated or even needed (Garehkhani, et. al., 2015).

Degree of freeness is one of indicator that generally used to express the degree of refining carried out on fibers. This is related with the ability of water to escape (drainage) from the fiber mat over the wire. The higher the level of fiber refining, water is more difficult to escape from fiber mat, or less water can escape from the fiber. In other words, the freeness of fibers is low. This is related to water drainage rate of sheet formation on paper machines' wire, as well as the speed and production capacity of paper machines. (Rahmanasari, 2011).

In paper industry, refining of fiber is an energy intensive process in terms of energy consumption (Chauhan et. al., 2009). The refining intensity and amount of energy used are important factors to produce the desired interfiber bonding. In the refining process, it is expected that fiber development takes place optimally with minimum energy consumption (Wikanaji and Trismawati, 2011). Therefore, the economic aspects of refining process should be carefully considered.

The selection of refining equipment and method depends on the target of paper quality to be made, the pulp raw material used, and its capacity (Luminianen, 1998). The type of refiner used must be considered to obtain an efficient refining process. There are three types of refiner used by the industry which is geometrically different, i.e. disk refiner, conical refiner, and cylindrical refiner. In principle, the refiner consists of a moving rotor and a static stator, with a various pattern of refiner plates depend on the fiber characteristics to be processed (Garehkhani, et.al., 2015).

In general, paper mills apply separate refining for their pulps. The choice of separate refining is usually done for different pulps. The choice of series depends on targeted refining results and capacity (Luminianen, 1998). Each type of pulps are refined separately in order to obtain the optimum fiber development. This requires not small amount of equipment investment.

Simultaneous refining of pulp mixtures, also known as combine-refining or mixed-refining, is also an option that can be applied. Simultaneous refining of two or more different type of pulps is called mixed refining (Luminianen, 1998). However, this needs to be considered carefully, especially in terms of type of pulp used and the expected of final fiber properties.

A laboratory study on mixed refining of softwood and hardwood has been reported by Panthai and Somboon (2014) which resulted in sheets with superior strength. The presence of hardwood provided important benefits in reducing drainage of mixed pulp which facilitate a good sheet formation. However, the properties of sheet resulted were greatly influenced by the composition of softwood and hardwood mixture which refined simultaneously.

The same study on mixed refining of softwood and hardwood also has been carreid out by Chauhan et. al. (2011). The results showed that better sheet strength were obtained and comparable to those of separate-refining.

The addition of hardwood in the refining process is usually a smart choice, because it decreases the refining energy. However, the use of hardwood will reduce the strength properties of sheet (Nugroho, 2012).

Another study on mixed-refining of BCTMP (bleached chemi-thermomechanical pulp) and Eucalyptus kraft 
pulp (EKP) has been investigated compared to separate refining. The results showed that mixed-refining was more energy efficient than separate refining. In addition, mixed-refining increased the surface smoothness and strength of sheet, and did not significantly influence the opacity and light scattering properties of the sheet (Gao et.al., 2009).

Both separate refining and mixed-refining have advantages and disadvantages. The most beneficial thing of mixed-refining is that it is more energy-efficient process; while the separate refining facilitates an optimum fiber development so that produce sheets with higher strength.

\section{Experimental}

The pulp used in this experiment were BCTMP originating from imports and Leaf Bleached Kraft Pulp of Acacia mangium obtained from one of the pulp mills in Riau Province, Indonesia, with the initial freeness of $380 \mathrm{~mL}$ CSF and $440 \mathrm{~mL}$ CSF respectively.

The experiment was carried out on a laboratory scale at the Center for Pulp and Paper, Bandung - Indonesia. The equipment involved in this experiment were laboratory beater, handsheet former, CSF (Canadian Standard Freeness) tester, microscope, analytical scales, and paper test equipment such as micrometers, tearing strength tester, tensile strength tester, bursting strength tester, Bendtsen type porosity and roughness tester, and optical properties tester.

Table 1. Fiber furnish composition

\begin{tabular}{|l|c|c|}
\hline \multicolumn{1}{|c|}{ Code } & BCTMP $(\%)$ & LBKP $(\%)$ \\
\hline L-1 & 100 & 0 \\
\hline L-2 & 0 & 100 \\
\hline L-3 (separate refining) & 10 & 90 \\
\hline L-4 (mixed refining) & 10 & 90 \\
\hline
\end{tabular}

In this experiment, the refining of BCTMP and LBKP were carried out separately until $300 \mathrm{~mL}$ CSF of freeness. Then, the handsheets of $80 \mathrm{~g} / \mathrm{m} 2$ were made with fiber furnish composition according to Table 1 (code L-1, L-2 and L-3). At the same pulp mixture composition with L-3, i.e. 10\% BCTMP and 90\% LBKP, a combined refining between these both pulps was carried out until $300 \mathrm{~mL}$ CSF of freeness and then the handsheets of 80 $\mathrm{g} / \mathrm{m} 2$ were also made (code L-4).

Evaluation of experimental results was carried out on fiber morphology, physical and optical properties of handsheets, and photograph of handsheets surface magnification using SEM (Scanning Electron Microscope). Fiber morphology determined were maximum, minimum and average fiber lengths, as well as fiber fractions of pulps from all treatments. Physical and optical properties evaluated including bulk, strength properties (tearing, tensile, and bursting strength), Bendtsen porosity and roughness, brightness and opacity.

\section{Results and Discussions}

4.1 Fiber Length

Figure 1 shows the maximum, minimum and average fiber length, while the Figure 2 shows the fiber fractions.

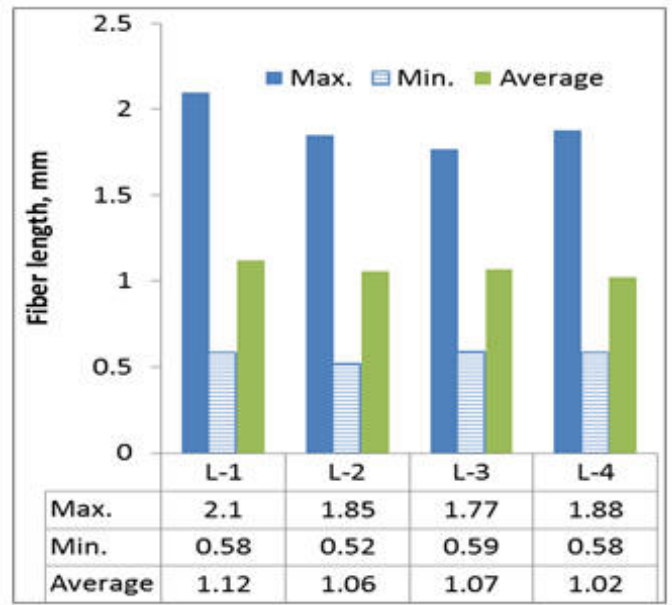

Figure 1. Fiber length

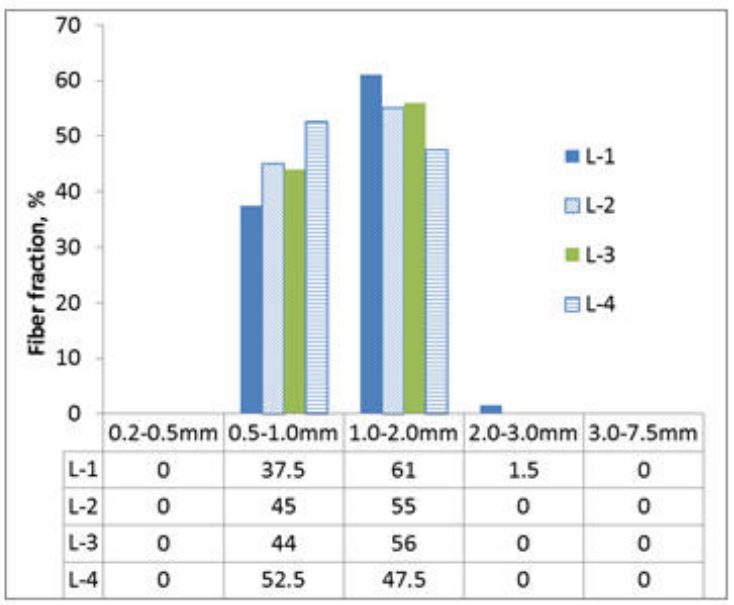

Figure 2. Fiber fractions

Figure 1 shows that the L-1 (BCTMP) had the highest maximum and average fiber length. It was higher than L-2 (LBKP). However, the average fiber length of both BCTMP (L-1) and LBKP (L-2) were classified as short fiber.

While the minimum fiber length was almost similar to a mixture of $10 \%$ BCTMP and $90 \%$ LBKP, both 
separate refining (L3) and combined refining (L-4). The minimum fiber length indicated by all treatments was relatively the same, which was in the range of $0.5 \mathrm{~mm}-0.6 \mathrm{~mm}$.

Figure 2 showed that the distribution of fiber length of all pulps were only spread over two fiber length fractions, i.e. fraction of $0.5 \mathrm{~mm}-1.0 \mathrm{~mm}$ and $1.0 \mathrm{~mm}-2.0 \mathrm{~m}$, except L-1 (BCTMP). There were a slight (1.5\%) fiber fraction of $2.0 \mathrm{~mm}-3.0 \mathrm{~mm}$ with the highest number of fiber fraction of $1.0 \mathrm{~m}-2.0 \mathrm{~mm}$, and the lowest number of fraction of $0.5 \mathrm{~m}-1.00 \mathrm{~mm}$. The combined refining treatment (L-4) resulted in the highest number of fiber fraction of $0.5 \mathrm{~mm}-1.0 \mathrm{~mm}$ with the lowest number of fraction of $1.0 \mathrm{~mm}-2.0 \mathrm{~mm}$.

In the combined refining treatment (L-4), although the average fiber length was the lowest, the maximum fiber length was still quite good, close to the LBKP (L-2). Based on the previous studies showed in Figure 3, the freeness reduction of combined refining of 7\% BCTMP and 93\% LBKP mixture was almost similar than those of LBKP refining curve (Indriati et al., 2016).

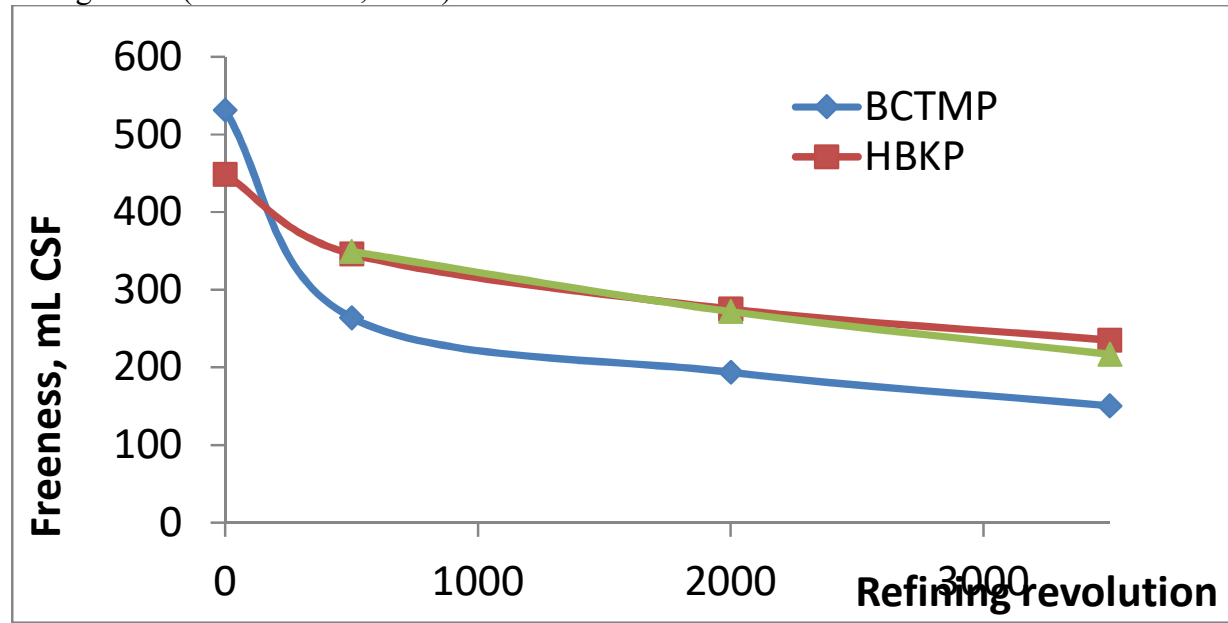

Figure 3. Refining curve BCTMP, LBKP and combined refining of 7\% BCTMP + 93\% LBKP (Source: Indriati et.al., 2016)

\subsection{Sheet Bulk}

Bulk of paper indicates the volume of paper per unit of its weight. The higher the bulk means that in the same weight the higher the sheets' volume. The paper bulk value is obtained from the division of the sheets' thickness by its grammage, expressed in $\mathrm{cm}^{3}$ per gram.

Figure 4 shows the BCTMP (L-1) having the highest sheet bulk. In contrast, LBKP indicates the lowest bulk properties.

Compared to LBKP (L-2), a slight increasing in bulk were occurred on the sheets made from mixed furnish of BCTMP and LBKP, both with separate refining (L-3) and combined refining (L-4). But, it was much lower than L-1 (BCTMP). This probably caused by the portion of BCTMP in the mixed furnish was only $10 \%$ compared to $90 \%$ of LBKP, so that the increasing of sheet bulk did not so significant.

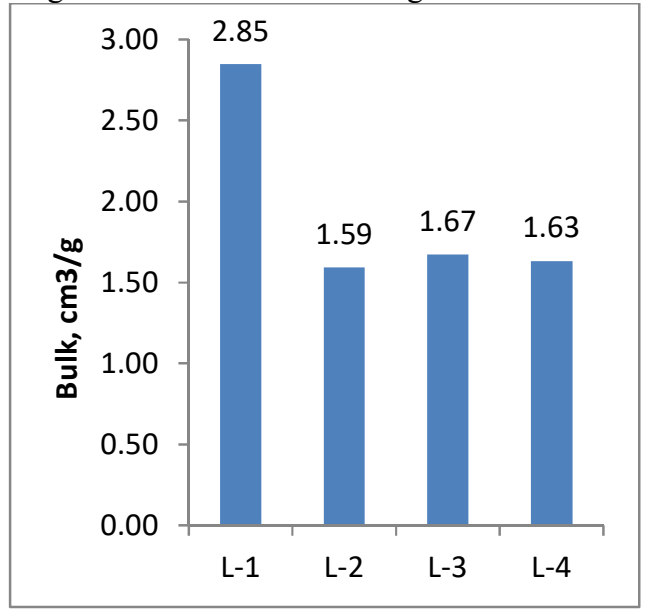

Figure 4. Sheet bulk 


\subsection{Strength Properties}

The strength properties evaluated in this experiment includes tensile, bursting and tearing strength. In Figure 5, 6 and 7, LBKP (L-2) shows higher strength properties compared to BCTMP (L-1). LBKP is a pulp made from hardwood which is short fiber, chemically cooked with kraft process, and bleached using elementally chlorinefree bleaching process. Bleached chemical pulp with low lignin content, generally has a pure cellulose content resulting in higher strength sheets compared to mechanical pulp.

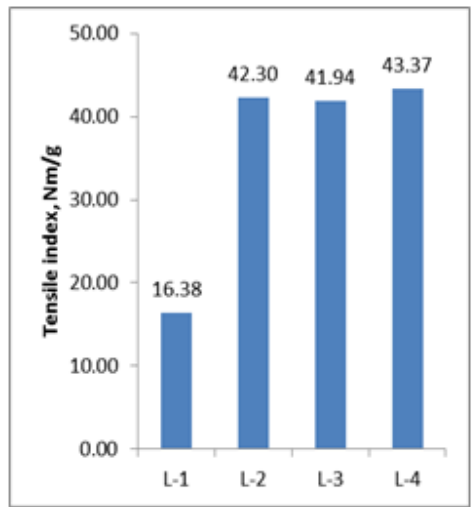

Figure 5. Tensile index

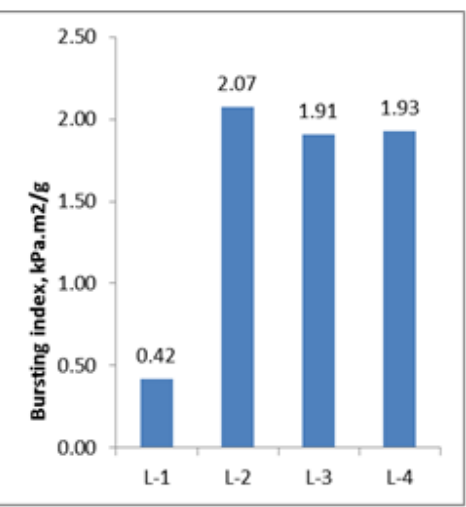

Figure 6. Bursting index

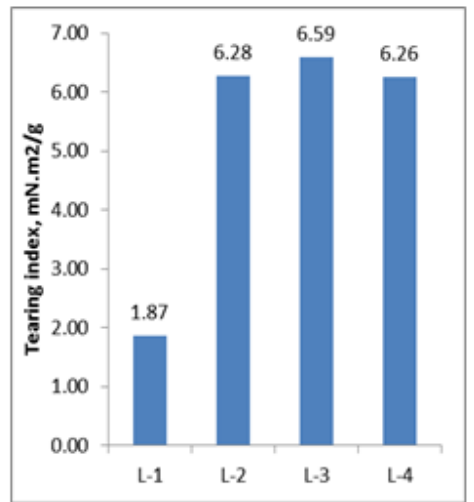

Figure 7. Tearing index

As one type of HYP, BCTMP fibers have an experienced a process of mechanical defiberation using a pressurized refiner, so that it can increase the occurrence of fiber cutting. This results in sheets with low strength properties. In addition, high lignin content in BCTMP causes fibers to become less absorbent of water. This will inhibit the occurrence of fiber swelling which is an important stage in the pulp refining process. At this stage, the fiber absorbs water and swells so that fiber fibrillation can be maximized. In the case of BCTMP, due to its high lignin content, fiber swelling cannot occur optimally which results in less fiber fibrillation.

The strength of sheets made from BCTMP and LBKP mixtures, both L-3 and L-4, have almost similar value to LBKP (L-2). This was because the relatively small number of BCTMPs used (10\%) compared to LBKP (90\%). Therefore, the decrease of paper strength due to the use of BCTMP was not significant.

The strength properties of sheets made from combined refining was almost similar to separate refining. Thus, it can be said that combined refining the mixture of 10\% BCTMP and 90\% LBKP can be considered because in addition to reducing production costs through the use of BCTMP as a substitute for LBKP, it can also save refining energy, which can also reduce the production costs.

\subsection{Porosity}

The porosity indicates indirectly the existence of pores within the paper, i.e a microsopic holes which connect both surfaces of paper. Generally, the paper porosity is determined using a testing equipment of the air-leak method. One of this equipment is namely Bendtsen which was used in this experiment. In use of Bendtsen testing equipment, the value of porosity is expressed as the flow rate of air in $\mathrm{mL} / \mathrm{min}$ that penetrates both surfaces of paper. The higher the air flow rate, the higher the porosity as well as the number of pores within the papers.

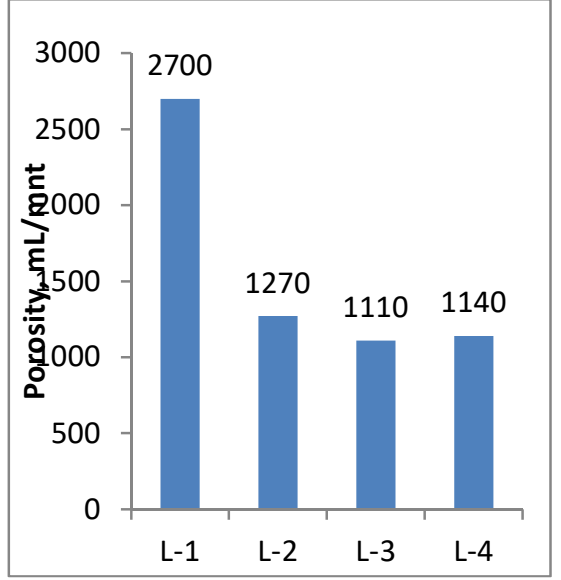

Figure 8. Porosity 
Figure 8 shows a lower porosity value of $100 \%$ LBKP (L-2) compared to $100 \%$ BCTMP (L-1). This is in line with the higher BCTMP sheet bulk compared to LBKP. In general, at the same grammage, paper with high bulk has a high porosity as well. The same trend was also seen in the use of 10\% BCTMP as a substitute for LBKP, both in separate refining (L-3) and combined refining (L-4), where the addition of BCTMP gave no significant effect on sheet porosity; even on the contrary, the porosity is lower than LBKP (L-2). However, the combined refining treatment slightly increased the porosity of sheets resulted.

\subsection{Roughness}

The roughness of paper surface indicates the contour of the paper surface. The roughness of paper is also determined using the air leak method. It is expressed by the rate of air flow that passes through the gap between the test equipment and the surface of paper. The greater the difference of paper surface contour, the higher the air flow rate, the higher the roughness of paper surface.

In Figure 9, the highest value of paper roughness, both top and bottom surfaces, were obtained by BCTMP sheets (L-1). This value was higher than LBKP (L-2) and a mixture of BCTMP and LBKP (L-3 and L-4). The high lignin content of BCTMP inhibits the fiber swelling occurrence, so that the optimum refining could not take place. This trend was similar with Figure 4 and 8 for bulk and porosity value of the BCTMP (L-1), which were also higher than the other three pulps (L-2, L-3 and L-4).

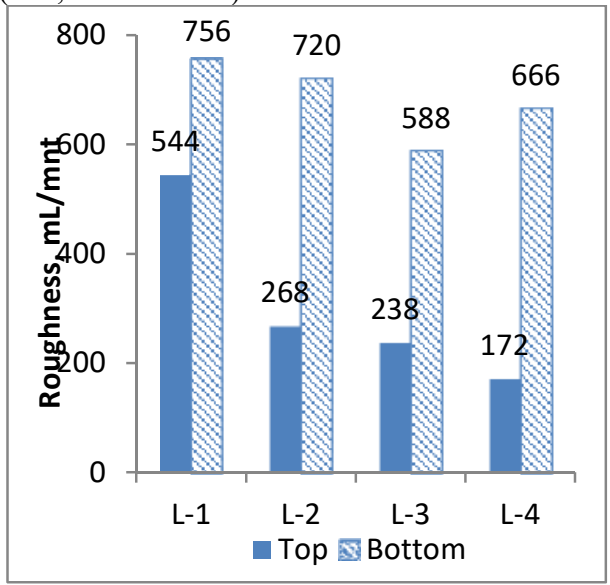

Figure 9. Surface roughness

The roughness of sheets made from pulp mixture with combined refining (L-4) showed slightly higher than the sheets from pulp mixture with separate refining (L-3). This was probably due to the fact that in combined refining it is difficult to achieve an optimum fiber fibrillation due to the different characteristics of the two types of pulp that being mixed.

However, the decreasing of paper surface roughness means the increse of paper smoothness which is an important and required characteristic particularly for writing and printing paper grades.

4.6 Optical Properties

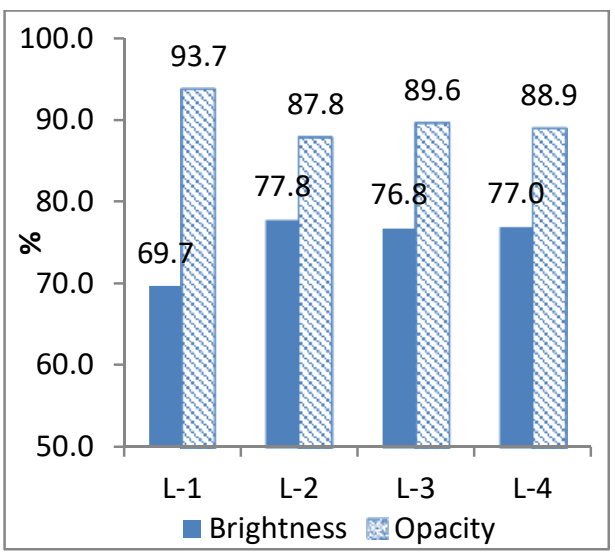

Figure 10. Brightness and opacity

Brightness of BCTMP (L-1) was lower than LBKP (L-2) and mixture of BCTMP and LBKP, both separate 
refining (L-3) and combined refining (L-4) (see Figure 10). The brightness value of BCTMP and LBKP mixture (L-3 and L-4) decreased slightly compared to LBKP (L-2). This was reasonable because the proportion of BCTMP in the mixture is only $10 \%$ compared to $90 \%$ of LBKP.

The opposite trend was seen for the opacity of the sheet, where the BCTMP (L-1) indicated the highest opacity. The use of BCTMP as a substitute for LBKP (L-3 and L-4) increased sheet opacity compared to LBKP (L-2). One of the advantages of using BCTMP as a substitute for LBKP is its ability to increase sheet opacity. Thus, the same sheet opacity can be achieved at lower paper grammage while still maintaining the other sheet properties.

\subsection{Sheet Surface Photographs}

From a sheet surface image with a magnification of 500 times (Figure 10), it is clearly visible the difference between the surface of BCTMP (L-1) and the other three sheets i.e L-2, L-3 and L-4. The image of the L-1 sheet surface contours was more varied, while the L-2, L-3 and L-4 were more flat. However, the image of L-3 and L-4 sheet surface contour were more varied than L-2. Separate refining (L-3) resulted in more even surface contours of the sheet compared to mixed refining (L-4). This is in accordance with Figure 9 which shows that the surface roughness of sheet L-3 is lower than that of L-4.

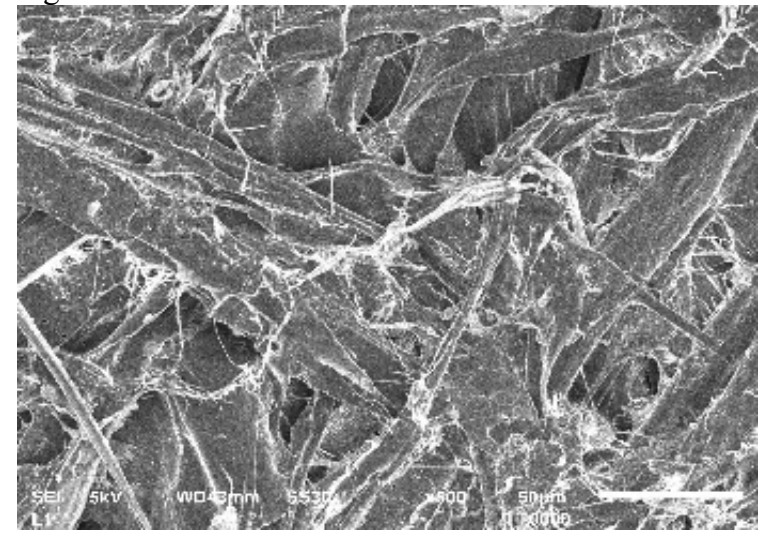

L-1

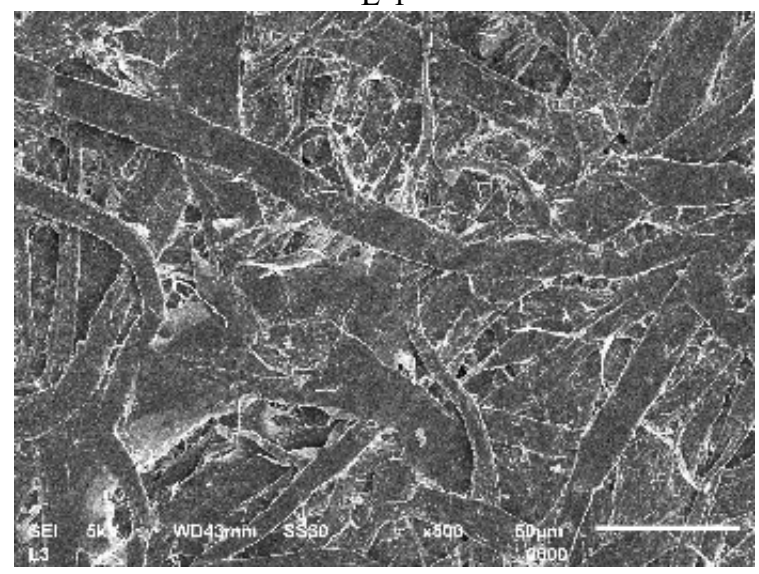

L-3

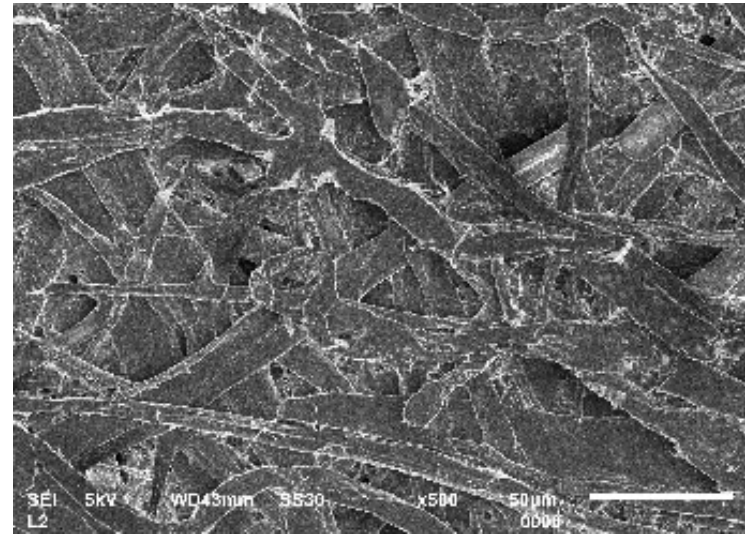

L-2

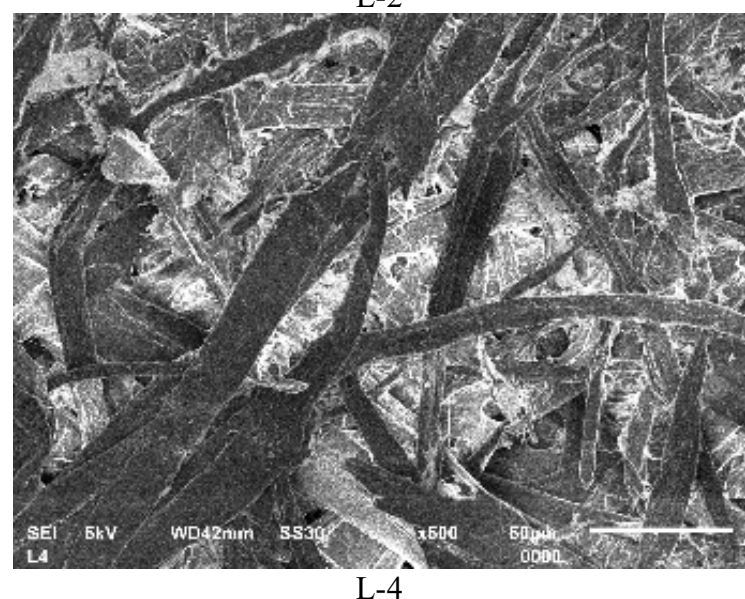

Figure 11. Image of sheets surface (500x magnification)

\section{Conclusion}

Mixed refining of 10\% BCTMP and 90\% LBKP mixture produced the lowest average fiber length, but its' maximum fiber length was quite similar with LBKP fibers. Although the bulk properties of BCTMP was higher than LBKP, the bulk properties of sheet produced was not affected significantly compared to $100 \%$ LBKP and the sheet bulk of the same pulps mixture which is refined separately. Compared to separate refining, mixed refining of pulps produced good strength properties, while the other sheet properties were not significantly influenced.

Acknowledgement

Gratitude is delivered to the Director of Center for Pulp and Paper, Ministry of Industry, who has given his supports up to this paper completed and submitted to be published. 


\section{References}

Hu, K., Ni, Y., Zhou, Y. \& Zou, X. (2006), "Substitution of Hardwood Kraft with Aspen High-Yield Pulp in lightweight coated wood-free papers", Tappi Journal 5(3), 2-26.

Liu, H., Chen, Y., Zhang, H., Yuan, Z., Zou, X., Zhou \& Y., Ni, Y. (201), "Increasing the Use of High-Yield Pulp in Coated High-Qualiy Wood-Free Papers: From Laboratory Demonstration to Mill Trials", Industrial \& Engineering Chemistry Research Vol. 51, 4240-4246.

Indriati, L., Kesuma, A. \& Juliani. (2016) “Sustitution of BCTMP for Hardwood Kraft Pulp in Writing and Printing Paper”, Proceedings of International Symsposium of $2^{\text {nd }}$ REPTech, 32-326.

Liu, H., Wang, Y., Yuan, Z., Zou, X., Zhou, Y. \& Ni, Y. (2014), "Effect of Using a High-Yield Pulp (HYP) Subsitution (40\%) on Printability and Print Quality of Coated Wood-Free Papers - A Comparison of Commercial Prints ans Lab Printed Samples", Colloids and Surfaces A: Physicocheical and engineering Aspects Vol. 452, 154-158.

Klinga, N., Höglund, H. \& Sandberg, C. (2007), "Energy Efficient High Quality CTMP for Paperboard”, Journal of Pulp and Paper Science 34(2), 98-106.

http://www.paperonweb.com/gradepl.htm, “Grades (Types) of Pulp” (Accessed at 13 June 2019).

Hu, K., Ni, Y. \& Zou, X. (2004), "Substitution of Aspen High-Yield Pulp for Hardwood Kraft Pulps in Fine Paper and Its Effect on AK Sizing", Tappi Journal 3(8), 13-16.

Gao, Y., Huang, F., Rajabhandari, V., Li, K. \& Zhou, Y. (2009), "Effect of Separate Refining and Co-Refining of BCTMP/KP on Paper Properties", Pulp and Paper Canada July/August, 28-33.

www.sicemsaga.com "Increase High-Yield Pulps in Fine Paper Furnish" (Accessed 13 June 2019).

Chen, Q., Ni, Y. \& He, Z. (2012), "Using Cationic Polymers to Improve Alkenyl Sucinic Anhydride (ASA) Sizing Efficiency in High-Yield Pulp Containing Furnish", BioEsources 7(3), 3948-3959.

$\mathrm{Pu}$, Y., Anderson, S., Lucia, L. \& Ragauskas, A.J. (2003), "Fundamentals of Photobleaching Lignin Pat I: Photobehaviours of Acetylated Softwood BCTMP Lignin”, Journal of Pulp and Paper Science 29(1), 401406.

Chauhan, V. S., Kumar, N., Kumar, M., Chakrabarti, S. K., \& Thapar, S. K. (2011), "Effect of Separate and Mixed Refining of Hardwood and Softwood pulps on Paper Properties", Journal of Korea TAPPI 43(4),

Lumiainen, J., (1998), "Refining of Chemical Pulp", Papermaking Part, Stock Preparation and Wet End p 1-20.

Nugroho, D.D.P., (2012), "Low Consistency Refining of Mixtures of Softwood \& Hardwood Bleached Kraft Pulp : Effects of Refining Power", Master Thesis, School of Environment, Resources and Development, Asian Institute of Technology, Thailand.

Panthai, S. \& Somboon, P. (2014), "Examination of Separate and Mixed Refining Methods on Softwood and Hardwoood for Linerboard Production”, Kasetsart J. (Nat. Sci.) 48(4), 540-547.

https://www.pulpandpapercanada.com/news/bctmp-a-pulp-for-all-reasons-1000106738, "BCTMP: A Pulp for All Reasons?" (Accessed at 13 June 2019).

Garehkhani, S., Sadeghinezhada, E., Kazia, S.N., Yarmanda, H., Badarudin, A., Safaei, M.R., and Zubir, M.N.M. (2015), "Basic effects of pulp refining on fiber properties-A review", Carbohydrate Polymers 115, Elsevier, 785-803.

Pettersson, G., Höglund, H., Norgren, S., Sjöberg, J., Peng, F., Hallgren, H., Moberg, A., Ljungqvist, C-H., Bergström, J., and Solberg, D. (2015), "Strong and bulky paperboard sheets from surface modified CTMP, manufactured at low anergy", Nordic Pulp \& Paper Research Journal 30(2), 319-325.

Xu, E.C., and Zhou, Y. (2007), "Synergistic effects between chemical mechanical pulps and chemical pulps from hardwoods", Tappi Journal 6(11), 4-9.

Rahmanasari, H. and Hidayat, T. (2011), "Effectiveness of various refining indicators to predict paper quality", Jurnal Selulosa 1(2), 72-80.

Hou, Q., Yang, B., Liu, W., Liu, H., Hong, Y., and Zhang, R. (2011), "Co-refining of wheat straw pulp and hardwood kraft pulp", Carbohydrate Polymers 86, 255-259

Wikanaji, D. and Trismawati. (2011), "Fiber development and energy efficiency in refining combination of high and low consistency", Prosiding Seminar Teknologi Pulp dan Kertas 2011, p.22-28

Bicho, P. (2018), "The effects on tissue quality of softwood and hardwood pulp preparation: Results from a pilot tissue pilot PM trial, Tissue World, Miami, (Available at https://www.tissueworld.com/.../ 013 Canfor\%20Pulp PaulBi...) (Accessed 11 July 2019) 